\title{
Ruang kelas virtual: pembelajaran dengan pemanfaatan permainan online Hago
}

\author{
Maulana Reza Palevi ${ }^{1}$, Pipit Amalia Saputri ${ }^{2}$, Intan Ayu Saridewi ${ }^{3}$ \\ ${ }^{123}$ Universitas Muhammadiyah Surakarta
}

\begin{tabular}{l} 
Article Info \\
\hline Article history: \\
Received Des $21^{\text {th }}, 2019$ \\
Revised Apr $23^{\text {rd }}, 2020$ \\
Accepted May $05^{\text {th }}, 2020$ \\
\hline
\end{tabular}

Keyword:

Hago

Virtual classes

Utilization

\begin{abstract}
Game users today have a lot, ranging from children to adults. Even parents are now starting to play the game as free time to get rid of boredom. Online games are now a favorite for users. The Hago application not only presents a number of game options, but the application can be used in the world of education, such as the use of chat rooms with several menu choices in it. With the chat room feature, users can communicate remotely, especially students and teachers in terms of learning. The purpose of this study is to describe the use of Hago chat Room as a virtal classroom for students. The type of research is descriptive qualitative. The data in the form of recorded chat room user conversations, while the data source in this study is the chat room menus in Hago. Data collection techniques are done by recording several menus in the chat room and data analysis techniques, namely analyzing the menus in the chat room into a virtual classroom. The results showed that the chat room has benefits in the world of education, namely virtual classrooms by utilizing the menus in the chat room.
\end{abstract}

\section{Corresponding Author:}

Maulana Reza Palevi,

Universitas Muhammadiyah Surakarta

Email: maulanarezaplv@gmail.com

\section{Pendahuluan}

Zaman yang sudah canggih ini telah menjadikan teknologi berkembang semakin pesat dan maju. Penggunaan aplikasi berbasis android semakin digemari banyak orang, terutama game-game yang ada di android. Banyak orang memainkan game android sekadar untuk hiburan dan mengisi waktu luang. Game online sekarang banyak diminati orang karena memberikan keseruan tersendiri. (Hanny H dan Rahmatsyam L, 2012) menyatakan bahwa game pada umumnya merupakan sesuatu yang dipakai sebagai sarana hiburan, tapi sekarang game lebih dikembangkan dan diperbarui sebagai alat pembelajaran dalam dunia pendidikan. Penggunaan dan pemanfaatan game sebagai alat pembelajaran dalam lingkup pendidikan pada umumnya bertujuan agar proses belajar mengajar menjadi lebih menyenangkan dan tidak bosan sehingga materi pelajaran lebih mudah dipahami. Pembelajaran berbasis game dapat memberikan stimulus pada tiga bagian penting dalam pembelajaran yaitu emosi, kecerdasan, dan psikomotorik. Manfaat menggunakan game dalam dunia pendidikan dapat memperlancar dan mempermudah dalam proses suatu pembelajaran sehingga tujuan pelajaran tidak terkendala.

Game mempunyai fungsi dan manfaat positif bagi anak, diantaranya, anak mengenal teknologi komputer, pelajaran untuk mengikuti pengarahan dan aturan, latihan memecahkan masalah dan logika, melatih saraf motorik dan keterampilan spasial, menjalin komunikasi anak dengan orangtua saat bermain bersama, serta 
memberikan hiburan. Bahkan, bagi pasien tertentu, permainan game dapat digunakan sebagai terapi penyembuhan (Samuel Henry, 2010). Game sebenarnya penting untuk perkembangan otak, untuk meningkatkan konsentrasi dan melatih untuk memecahkan masalah dengan tepat dan cepat karena dalam game terdapat berbagai konflik atau masalah yang menuntut kita untuk menyelesaikannya dengan cepat dan tepat (Wahyu, 2010).

Seiring dengan berkembangnya teknologi sekarang ini seharusnya bisa dimanfaatkan dengan tepat karena dengan memanfaatkan teknologi bisa membantu dan mempermudah dalam berbagai hal terutama dalam hal belajar. Penelitian (Dora Irsa dkk, 2015) menyatakan pada masa anak-anak daya tangkap sangat tinggi, dimana anak bisa mampu mengingat 20\% itu dari yang dilihat dan 30\% itu dari yang didengar dan orang mengingat $50 \%$ dari yang dilihat dan didengar serta $80 \%$ dari yang dilihat, didengar dan dilakukan.

Diperlukan sebuah sarana pembelajaran yang bisa memaksimalkan daya tangkap anak untuk membantu anak belajar dengan cara melihat, mendengar dan melakukan. Salah satunya teknologi yang terus berkembang pesat dan dianggap bisa memberikan pembelajaran yang menyenangkan adalah dengan melibatkan suatu game, karena game menggabungkan antara media lagu, teka teki dan permainan sehingga pembelajaran menjadi lebih menyenangkan dan tidak mudah bosan. Game sebenarnya akan sangat bermanfaat jika dimanfaatkan dengan positif, seperti game yang berfungsi sebagai sebuah media edutainment yaitu media yang menggabungkan antara unsur edukasi dengan hiburan atau biasanya sering disebut bermain sambil belajar.

Menurut (Dian dkk, 2016) terdapat banyak fitur game yang tidak hanya sebagai hiburan bermain, namun sudah banyak game untuk mengasah daya pikir dan logika yang dapat memperkenalkan materi agar lebih menarik untuk diterima dan dipahami terutama oleh anak yang masih dalam usia dini. Selanjutnya penelitian yang dilakukan (Wahyu, 2014) menyatakan bahwa cerita yang kuat akan menambah nilai pada sebuah game. Pemain akan berasa ada dalam cerita game itu. Sedangkan cerita yang unik dan menarik di sebuah game sebagai nilai tambah yang membedakan dari game lainnya. (Yogi S dan Bambang E.P, 2013) meneliti tentang "Rancang Bangun Aplikasi Mobile Game Edukasi Ilmu Pengetahuan Alam" hasilnya disimpulkan dengan adanya aplikasi mobile game edukasi mengenai tentang mata pelajaran ilmu pengetahuan alam, suasana belajar siswa akan bisa lebih menyenangkan dibandingkan metode belajar yang lama. Game mampu memberi motivasi kepada siswa agar semangat dalam belajar. Game mobile yang digunakan dalam pembelajaran mempunyai peran penting dalam membangun dan membentuk semangat belajar siswa agar pembelajaran tidak membosankan.

Game yang mengandung unsur tentang edukasi memiliki peran dalam dunia pendidikan. Hal ini dijelaskan dalam penelitian (Dony Novaliendry, 2013) menyatakan bahwa pembuatan game edukasi dilakukan untuk menunjang media pembelajaran di sekolah dengan cara belajar simulasi melalui game edukasi. Game edukasi dibuat dengan unsur media yang berupa teks, grafis, animasi, dan suara yang disajikan secara interaktif. Game edukasi berfungsi untuk menumbuhkan pengetahuan, keterampilan, kecerdasan, emosi, dan nilai-nilai sikap. Game edukasi adalah permainan yang dikembangkan untuk tujuan pendidikan dimana memiliki karakteristik pendidikan dan menghibur (Budi dan Endah, 2016). Game berjenis edukasi bertujuan untuk memancing minat belajar anak terhadap materi pelajaran sambil ber-"game", sehingga dengan perasaan senang diharapkan siswa bisa lebih mudah memahami materi pelajaran yang disajikan (Jada dkk, 2016).

Game online memiliki beraneka ragam model. Menurut (Maria, 2016) game online sendiri memiliki model, serta bentuk menarik yang berisi gambar-gambar animasi, tampilan, gaya bermain, permainan peran, pertualangan, balapan, sepak bola, pertarungan, tembak menembak dan masih banyak lagi yang mendorong siswa bahkan orang dewasa tertarik bermain game. (Nanan R dan Bambang M, 2010) menyatakan ada beberapa kriteria game edukatif antara lain sebagai berikut: (1) Pembelajaran: program dapat digunakan untuk pembelajaran individu, kelompok kecil, program mempunyai topik yang jelas, Pendekatan game edukatif dalam program sesuai, dan dapat menyesuaikan anak, (2) Isi game: isi game mempunyai konsep yang benar dan tepat, program memiliki materi konsep, program memiliki soal test, (3) Interaksi: struktur program fleksibel terhadap pengguna, program mempunyai balikan terhadap input yang diberikan oleh pengguna, (4) Balikan: balikan bersifat positif dan tidak membuat pengguna cepat menyerah, balikan relevan terhadap respon pengguna, balikan korektif, balikan memiliki respon yang bervariasi sehingga pengguna tidak merasa bosan, balikan tetap tampil dalam waktu yang sesuai, balikan mendorong anak untuk berusaha dalam memeperoleh jawaban yang benar, (5) Penanganan masalah: pengguna dapat mengoreksi kesalahan dalam memasukkan input kecuali yang benar.

Menurut (Oktavia dkk, 2015) game edukasi adalah salah satu jenis media yang digunakan untuk memberikan suatu pengajaran, menambah pengetahuan penggunanya melalui suatu media yang unik dan 
menarik. Jenis ini biasanya ditujukan untuk anak- anak, maka permainan warna sangat diperlukan disini bukan tingkat kesulitan yang dipentingkan. Game edukasi adalah game digital yang dirancang untuk pengayaan pendidikan (mendukung Pengajaran dan pembelajaran), menggunakan teknologi multimedia interaktif dan mempunyai kesempatan yang baik dengan berbasis game (Karli, 2015).

Pemilihan game dalam penerapan metode pembelajaran berbasis game harus mempertimbangkan beberapa aspek, antara lain: (1) Ketersedian unsur edukasi, (2) Konten materi yang mengandung capaian pembelajaran, (3) Segi permainan yang dapat meningkatkan kreativitas, dan (4) Pola permainan yang dapat memicu kemampuan berpikir kritis (Sukirman, 2017).

Aktivitas pembelajaran yang berbasis online relatif lebih tertata apabila dibandingkan dengan aktivitas pembelajaran yang pendokumentasiannya berbasis manual. Tugas yang dikirimkan oleh mahasiswa dan tinjauan dari dosen dapat dikategorikan dan dikelompokkan berdasarkan pertimbangan tertentu. Hal ini akan memudahkan dosen melihat dan mengomentari tugas mahasiswa (Huda, 2017). Strategi berpikir integratif adalah strategi yang mengkondisikan siswa pada suatu keadaan yang memungkinkan untuk mengembangkan konstruksi pengetahuan secara sistematis, sekaligus mengembangkan kemampuan berpikir kritis (Huda, 2018).

\section{Metode}

Jenis penelitian ini adalah deskriptif kualitatif yaitu untuk mendeskripsikan ruang kelas virtual dengan memanfaatkan permainan Hago. Data penelitian berupa menu-menu dalam ruang obrolan. Sumber data berupa materi bahasa Indonesia yang diberikan melalui ruang obrolan. Materi berupa bentuk lisan atau bisa ditampilkan dalam bentuk audio visual. Teknik pengumpulan data dengan mencatat beberapa menu-menu di ruang obrolan dan teknik analisis data yaitu menganalisis menu-menu di dalam ruang obrolan menjadi ruang kelas virtual

\section{Hasil dan Pembahasan}

Secara umum, proses belajar mengajar identik dengan adanya pertemuan tatap muka antara guru dan siswa yang berlangsung di dalam kelas. Guru akan memberi materi dan siswa menjadi subjek penerima materi. Interaksi antara guru dan siswa pun terjadi secara langsung. Apabila guru berhalangan hadir di kelas maka proses pembelajaran akan terhambat. Padahal dengan adanya perkembangan teknologi saat ini, pembelajaran dapat berjalan lebih mudah yaitu dengan memanfaatkan sebuah aplikasi android. Aplikasi Hago merupakan salah satu media sosial berupa permainan. Aplikasi Hago terdapat ruang obrolan dimana pengguna akun dapat berinteraksi saling berkomunikasi jarak jauh.

Ruang kelas virtual adalah salah satu kelas alternatif dalam bentuk maya dengan memanfaatkan aplikasi permainan Hago sebagai pengganti kelas nyata. Tidak adanya seorang guru dalam mengajar di dalam kelas, proses belajar mengajar tetap bisa terlaksana dengan menggunakan kelas virtual Hago. Berikut ilustrasi kelas virtual dengan memanfaatkan permainan Hago.

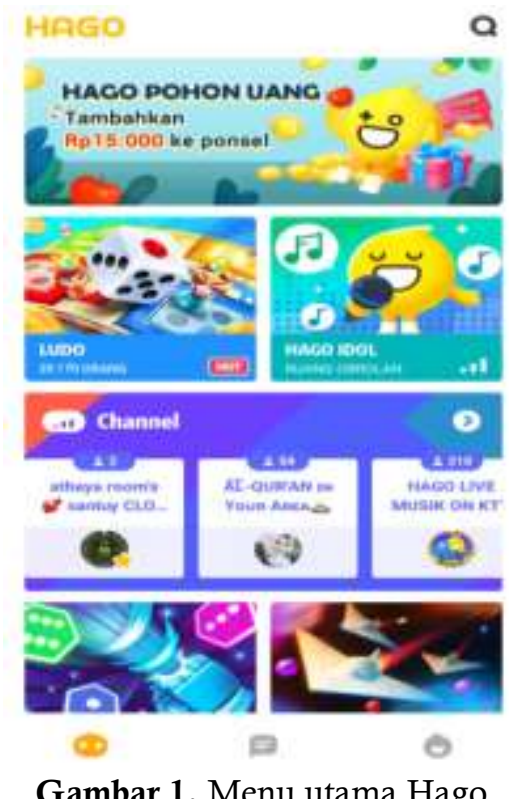




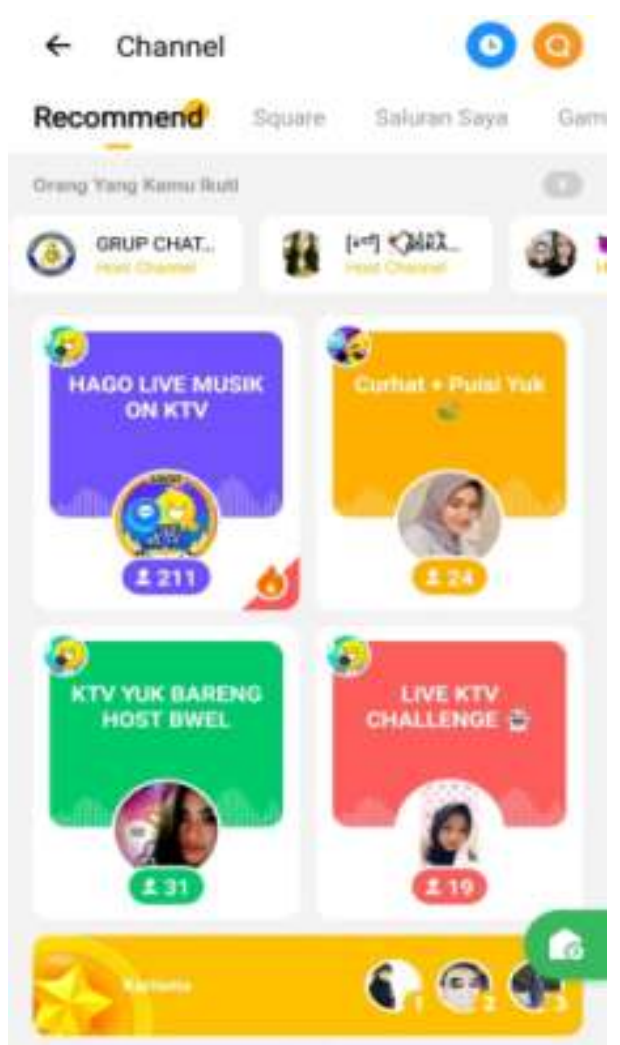

Gambar 2. Menu ruang obrolan

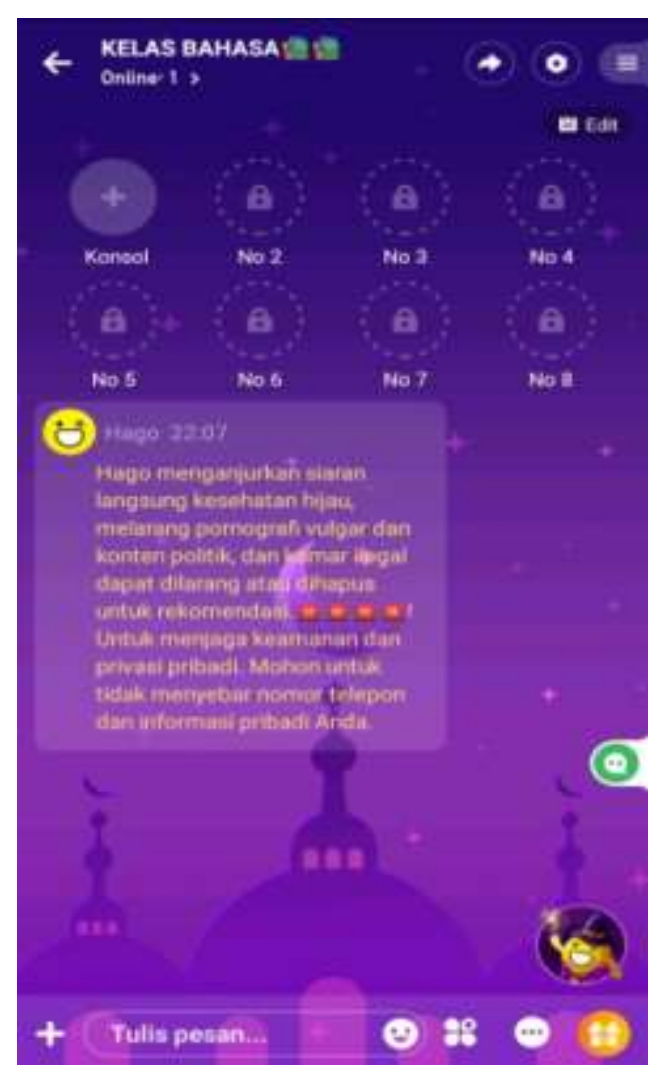

Gambar 3. Ruang kelas virtual

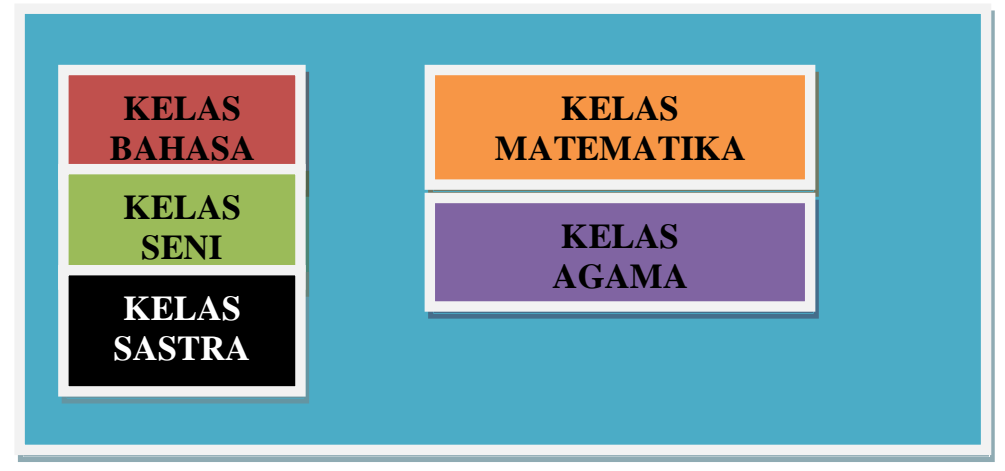

Ilustrasi di atas merupakan menu-menu pilihan yang ada di ruang obrolan. Adapun menu pilihan seperti kelas bahasa, kelas matematika, kelas seni, kelas agama, kelas sastra dan lain-lain. Siswa dapat memilih kelas virtual sesuai jadwal pelajaran. Menu kelas tersebut dibuat oleh guru yang sekaligus sebagai tuan rumah atau pemilik kelas virtual. Sebelum masuk ke menu-menu kelas virtual, guru maupun siswa harus memiliki akun Hago terlebih dahulu. Tidak hanya guru, siswa dapat membuat ruang kelas virtual sendiri.

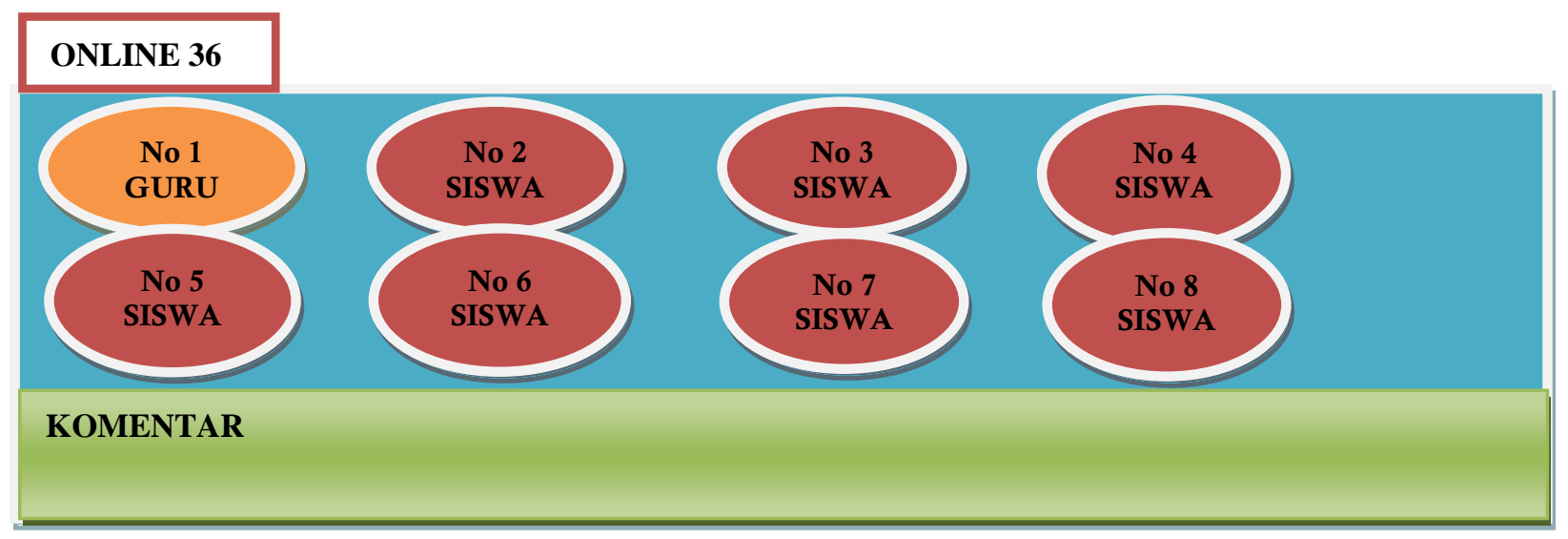


Ilustrasi di atas merupakan kelas virtual bahasa. Setelah siswa memilih menu kelas virtual, siswa langsung masuk ke dalamnya. Di dalam kelas virtual ada jumlah delapan kursi, mulai dari yang pertama untuk gurunya sebagai pemilik kelas dan sebagai pengendali kelas. Selain itu, kursi nomor dua sampai delapan untuk siswanya. Siswa yang tidak mendapat kursi hanya bisa mendengarkan dan berkomentar di bawah. Setelah semua masuk kelas virtual, guru memberikan materi dalam bentuk lisan yaitu dengan menggunakan mikrofon. Guru bisa memberikan materi melalui audio visual. Siswa yang duduk di kursi bisa memberikan pertanyaan kepada guru melalui mikrofon. Siswa yang tidak duduk di kursi, bisa memberikan komentar di bawah. Dengan kelas virtual, proses belajar mengajar dapat terlaksana sesuai tujuan. Meskipun guru tidak bisa mengajar, tetapi dengan adanya kelas virtual guru dapat memantau dari kejauhan tanpa harus masuk ke ruang kelas. Siswa dapat berdiskusi dengan temannya jika ada tugas dari guru yaitu dengan membuka kelas virtual sendiri dimanapun dan kapanpun tanpa harus bertemu langsung dengan orangnya.

Kelas virtual Hago mempunyai manfaat dalam dunia pendidikan. Seperti memperlancar proses belajar mengajar dalam mencapai sebuah tujuan. Kelas virtual Hago dapat berkomunikasi secara bersama dengan menggunakan fitur seperti audiovisual, teks chat, emoticon, dan memakai ruangan terpisah. Konsep pembelajaran secara virtual (maya) yakni guru dan siswa tetap bisa melakukan komunikasi secara bersama tanpa harus bertemu secara langsung.

Penelitian yang dilakukan (Hardiyana. 2015) bahwa kelas virtual (virtual class) merupakan kelas yang berbasiskan pada web, jadi guru dan murid dapat berinteraksi dan berkomunikasi kapan saja dan dimana saja tanpa dibatasi oleh ruang dan waktu. Sama seperti di kelas konvensional, dalam pembelajaran yang dilakukan di kelas virtual maka siswa dan guru dapat berinteraksi dengan satu sama lain, yang berarti siswa masuk ke kelas virtual pada saat yang sama tanpa harus bertatap muka dengan guru.

Dalam kelas virtual menciptakan suasana yang sama seperti kelas konvensional pada umumnya, tetapi berbeda dalam hal siswa dan guru tanpa harus bertatap muka. Dalam penelitian (Grandys dan Ahmad, 2011) mereka meneliti tentang "Virtual Class Sebagai Strategi Pembelajaran Untuk Peningkatan Kualitas Student Centered Learning Di Perguruan Tinggi" menyatakan bahwa (1) kelas virtual harus dapat menciptakan suatu lingkungan belajar yang kondusif. Selain itu, kelas virtual harus menciptakan suasana belajar di kelas yang lebih interaktif dan dinamis. (2) kelas virtual harus dapat menyediakan berbagai wadah fasilitas perkuliahan yang terintegrasi (tugas-tugas, bahan kuliah, rencana pembelajaran, dan penilaian hasil belajar) dan dapat mengukur beberapa pencapaian kompetensi mahasiswa. (3) kelas virtual perlu dirancang supaya siswa dapat berbagi suatu hasil karya dan bertukar pengalaman dalam menerapkan pengetahuan yang telah diperolehnya. (4) kelas virtual harus dapat meningkatkan dan menumbuhkan suatu motivasi kuliah mahasiswa karena kebanyakan mahasiswa cenderung malas datang ke kampus untuk kuliah dan mengabaikan pentinnya absensi dengan cara titip absen ke temannya.

Kelas virtual dapat membawa situasi dan suasana kelas nyata ke dalam teknologi dan mengubah situasi belajar mengajar yang seolah-olah seperti menjadi nyata. Hal serupa pada penelitian (Florence Martin, 2014) yang menyatakan bahwa virtual classrooms allow students and instructors to communicate synchronously using features such as audio, video, text chat, interactive whiteboard, application sharing, instant polling, emoticons, and breakout rooms. Artinya kelas maya memungkinkan siswa dan guru untuk berkomunikasi secara bersama dengan menggunakan fitur seperti audio, video, teks chat, papan tulis interaktif, berbagi aplikasi, polling instan, emoticon, dan memakai ruangan terpisah. Konsep pembelajaran secara virtual (maya) ini yaitu guru dan siswa tetap bisa melakukan suatu komunikasi secara bersama tanpa harus bertemu secara langsung atau bertatap muka saat jam pembelajaran.

Dalam kelas virtual Hago, siswa dapat memilih kelas tanpa harus pindah ruang tempat saat jam pelajaran berganti. Sedangkan guru tidak perlu masuk kelas jika ada urusan mendadak di luar sekolah dan tidak bisa hadir di kelas. Maka guru cukup membuka aplikasi kelas virtual Hago tanpa harus berta tap muka dengan siswa di kelas. Manfaat lainnya menggunakan kelas virtual Hago yaitu memberikan umpan balik atau tenggapan secara langsung, mendorong pertukaran berbagai pendapat, meningkatkan interaksi antara siswa, memperkuat sisi sosial, dan mendorong pertukaran emosional dan memasok unsur verbal. Kelas virtual Hago memudahkan siswa dalam diskusi kelompok. Jika nanti diberi tugas dari guru, siswa bisa membuka kelas sendiri dimana saja tidak harus bertemu dengan teman langsung di kelas.

Selain itu penelitian yang dilakukan (Ria Sudiana, 2017) menyatakan bahwa mahasiswa pada kelas yang menggunakan kelas virtual mempunyai indikator inisiatif belajar yang cenderung lebih baik, mendiagnosa mengevaluasi proses dan hasil belajar, self efficacy (konsep diri), tetapi masih lemah pada indikator dalam menetapkan target dan tujuan belajar dibandingkan siswa yang memperoleh pembelajaran konvensional. 
Sedangkan (Eko, 2017) menyatakan kelas virtual dapat meningkatkan aktivitas belajar siswa, guru harus lebih aktif dan kreatif lagi dalam memanfaatkan metode pembelajaran. Karena melalui penggunaan pembelajaran dengan kelas virtual dapat meningkatkan hasil belajar siswa.

Guru sebagai pemilik kelas virtual Hago memberikan materi lisan karena dalam kelas virtual terdapat mikrofon yang berfungsi sebagai jalan suara dalam berbicara saat menerangkan materi. Guru bisa tahu siswa yang hadir dan yang tidak hadir karena dilihat jumlah akun yang masuk ke kelas virtual. Guru bisa menghukum siswa dengan cara mengeluarkan siswa dari kelas virtual atau. Guru bisa memberi hadiah ke siswanya karena ada fitur gift semacam hadiah dari akun ke akun lainnya saat masuk ke dalam kelas virtual Hago.

\section{Kesimpulan}

Hasil dari penelitian kelas virtual Hago yaitu dengan adanya aplikasi kelas virtual Hago kita dapat dengan mudah berkomunikasi secara bersama menggunakan didalamnya seperti Audio visual, teks chat, emoticon, dan memakai ruangan terpisah. Selain itu dilengkapi pula dengan konsep pembelajaran secara virtual yakni guru dan siswa tetap bisa melaksanakan pembelajaran secara bersama-sama tanpa harus bertemu langsung. Siswa juga bisa memilih kelas tanpa harus berpindah kelas saat pergantian jam pelajaran. Sedangkan guru tidak perlu masuk kelas terlebih dahulu jika ada urusan mendadak di luar sekolah, dan apabila guru mendadak ada urusan sehingga tidak bisa hadir di kelas untuk menyampaikan materi, sekarang tidak perlu khawatir tertinggal materi karena dengan aplikasi ini guru hanya cukup membuka aplikasi kelas virtual Hago untuk membetikan materi. Materi tersebut akan diberikan secara lisan karena di dalam aplikasi tersebut terdapat micrifon yang berfungsi sebagai jalannya suara saat guru menyampaikan materi. Selain itu guru bisa mengetahui siapa saja siswa yang hadir dan siswa yang tidak hadir. Selanjutnya guru juga bisa memberikan sanksi kepada siswa dengan cara mengeluarkan dari kelas virtual.

\section{Referensi}

Budi, Eko N. 2017. Penerapan Pembelajaran Virtual Class Pada Materi Teks Eksplanasi Untuk Meningkatkan Aktivitas Dan Hasil Belajar Bahasa Indonesia Siswa Kelas XI IPS 2 SMA 1 Kudus Tahun 2017. Jurnal Pendidikan Ilmu Sosial. Vol. 27. No. 2:63-64.

Darmanto, B dan Endah S. 2016. Game Edukasi Dampak Pergaulan Bebas. Jurnal Protek. Vol. 3 No. 2:51.

Frieska, G dkk. 2011. Virtual Class Sebagai Strategi Pembelajaran Untuk Peningkatan Kualitas Student-Centered Learning Di Perguruan Tinggi. Teknologi. Vol 1. No. 2:97.

Hardiyana, Andri. 2015. Implementasi Google Classroom sebagai Alternatif dalam Meningkatkan Mutu Pembelajaran di Sekolah. Karya Tulis Ilmiah. Cirebon: SMA Negeri 1 Losari.

Haryanto, H dan Lakoro, R. 2012. Game Edukasi "Evakuator" Bergenre Puzzle Dengan Gameplay Berbasis Klasifikasi Sebagai Sarana Pendidikan Dalam Mitigasi Bencana. Techno.COM. Vol 11. No.1:47-54.

Henry, Samuel. 2011. Cerdas Dengan Game, Jakarta: Gramedia Pustaka Utama.hal 9.

Huda, M. 2017. Blended Learning: Improvisasi Dalam Pembelajaran Menulis Pengalaman. Lensa: Kajian Kebahasaan, Kesusastraan, dan Budaya. Vol. 8 No. 2:123. https://doi.org/10.26714/lensa.8.2.2018.117$\underline{130}$

Huda, M. 2018. Strategi Berpikir Integratif Dalam Pembelajaran Membaca Lintas Kurikulum Di Sekolah Dasar. Vol. 1 No. 2:32. https://scholar.google.co.id/citations?user=2khmvhsAAAAJ\&hl=id\#

Irsa, D dkk. 2015. Perancangan Aplikasi Game Edukasi Pembelajaran Anak Usia Dini Menggunakan Linear Congruent Method (LCM) Berbasis Android. Jurnal Informatika Global. Vol 6. No. 1:7-8.

Martin, Florence. 2014. Use of Synchronous Virtual Classrooms: Why, Who, and How?. MERLOT Journal of Online Learning and Teaching. Vol. 10 No. 2: 192-209.

Huda, M. 2017. Blended Learning: Improvisasi Dalam Pembelajaran Menulis Pengalaman. Lensa: Kajian Kebahasaan, Kesusastraan, dan Budaya. Vol. 8 No. 2:123. https://doi.org/10.26714/lensa.8.2.2018.117130

Novaliendry, D. 2013. Aplikasi Game Geografi Berbasis Multimedia Interaktif(Studi Kasus Siswa Kelas IX SMPN 1 $R A O)$. Jurnal Teknologi Informasi \& Pendidikan. Vol 6. No. 2:112-113.

Nuhan, M. 2016. Hubungan Intensitas Bermain Game Online Dengan Prestasi Belajar Siswa Kelas IV Sekolah Dasar Negeri Jarakan Kabupaten Bantul Yogyakarta. Jurnal Pendidikan Guru Sekolah Dasar Edisi 6 Tahun ke-5. Vol 5. No.6:499.

Oktiavia, N dkk. 2015. Pembuatan Game Edukasi Berbasis Construct 2 Sebagai Media Pembelajaran Fisika Untuk Siswa Sekolah Menengah Pertama. Proseding Seminar Nasional Fisika dan Aplikasinya. Bale Sawala Kampus Universitas Padjadjaran Jatinangor. 
Pratama, W. 2014. Game Advanture Misteri Kotak Pandora. Jurnal Telematika. Vol 7. No. 2:13-14.

Putra, Dian dkk. 2016. Game Edukasi Berbasis Android Sebagai Media Pembelajaran Untuk Anak Usia Dini. Jurnal Informatika Merdeka Pasuruan. Vol. 1 No. 1:46.

Ramadhan, K dkk. 2015. Game Edukasi Tebak Gambar Bendera Negara Menggunakan Metode Linear Congruental Generator (LGC) Berbasis Android. Jurnal Informatika Global. Vol. 6 No.1:28.

Rohman, N dan Mulyanto, B. 2010. Membangun Aplikasi Game Edukatif Sebagai Media Belajar Anak-Anak. Jurnal Computech \& Bisnis. Vol 4. No. 1:53-58.

Siswanto, Y dan Purnama, B.E. 2013. Rancang Bangun Aplikasi Mobile Game Edukasi Ilmu Pengetahuan Alam Untuk Anak Kelas VI Sekolah Dasar. Journal Speed-Sentra Penelitian Engineering dan Edukasi. Vol 5. No.4:32-33.

Sudiana, S dkk. 2017. Kemandirian Belajar Mahasiswa Melalui Pembelajaran Berbasis Virtual Class. JPPM Vol. 10. No. 1:75-76.

Sukirman. 2017. Integrasi Pendidikan Karakter Pada Pembelajaran Berbasis Game Untuk Mengajarkan Perilaku Santun Di Media Sosial. Jurnal Pendidikan Ilmu Sosial. Vol. 27 No. 2:33.

Wibisono, W dan Lies Y. 2010. Perancangan Game Edukasi Untuk Media Pembelajaran Pada Sekolah Menengah Pertama Persatuan Guru Repulik Indonesia Gondang Kecamatan Nawangan Kabupaten Pacitan. Journal Speed. Vol. 2 No. 2:38.

Yustin, J dkk. 2016. Rancang Bangun Aplikasi Game Edukasi Pembelajaran Matematika Menggunakan Construct 2. Jurnal Sistem dan Teknologi Informasi. Vol. 1 No. 1:1. 